\title{
USO DA MILTEFOSINA COMO TERAPIA COMBINADA EM LEISHMANIOSE VISCERAL CANINA - RELATO DE CASO
}

Camila de Melo Costa Araújo1; Alisson de Souza Costa $^{2}$, Júlio Marcos Ribeiro Risso

1- Médica Veterinária/ Residente em Clínica Médica de Animais de Companhia, Universidade Federal de Uberlândia (UFU), Uberlândia - MG, Brasil. Email: camilamelocosta@hotmail.com.

2- Médico Veterinário/ Mestre, Doutorando e Preceptor do programa de residência de Medicina Veterinária - UFU, Uberlândia - MG, Brasil.

3- Médico Veterinário autônomo e graduado em Medicina Veterinária - UFU, Uberlândia - MG, Brasil.

Recebido em: 06/04/2018 - Aprovado em: 10/06/2018 - Publicado em: 20/06/2018 DOI: $10.18677 /$ EnciBio_2018A79

\begin{abstract}
A leishmaniose visceral canina (LVC) é uma doença de caráter zoonótica, causada pelo protozoário Leishmania chagasi, espécie semelhante à Leishmania infantum. A LVC representa um grave problema de saúde pública e é considerada uma doença potencialmente fatal, se não tratada precocemente e de forma adequada. Recentemente, uma nova droga baseada em miltefosina (Milteforan $®$ Virbac) teve seu registro autorizado para o uso veterinário no tratamento de LVC. O estudo teve como objetivo avaliar a eficácia da miltefosina como terapia combinada no protocolo de tratamento dessa doença em uma cadela de aproximadamente dois anos que foi atendida no hospital veterinário da Universidade Federal de Uberlândia (UFU) em Uberlândia, Minas Gerais (MG). A cadela exibia sinais clínicos e laboratoriais da doença e foi reagente nos testes sorológicos e positiva pelo PCR. O animal foi tratado com $2 \mathrm{mg} / \mathrm{kg}$ de miltefosina por via oral uma vez ao dia (SID), durante 28 dias, $10 \mathrm{mg} / \mathrm{kg}$ de alopurinol duas vez ao dia (BID) uso contínuo e 0,5 mg/kg de domperidona uma vez ao dia (SID) durante 60 dias. O animal foi monitorado em relação aos sinais clínicos e alterações laboratoriais a cada 30 dias após o inicio do tratamento, durante o período de três meses. Após três meses retornou, para realização do PCR-RT para quantificar a carga parasitária. De acordo com os resultados clínicos e laboratoriais a miltefosina como terapia combinada demonstrou ser eficaz no tratamento de LVC.
\end{abstract}

RESUMO

PALAVRAS-CHAVE: cão, leishmania, tratamento.

\section{USE OF MILTEFOSIN AS COMBINED THERAPY IN CANINE VISCERAL LEISHMANIOSIS - CASE REPORT}

\begin{abstract}
Canine visceral leishmaniasis (LVC) is a zoonotic disease caused by the protozoan Leishmania chagasi, a species similar to Leishmania infantum. LVC represents a serious public health problem, and is considered a potentially fatal disease, if not treated early and adequately. Recently, a new drug based on miltefosine (Milteforan ${ }^{\circledR}$ Virbac) has been authorized for veterinary use in the treatment of LVC. The aim of the study was to evaluate the efficacy of miltefosine as a combination
\end{abstract}


therapy in the treatment protocol of this disease in a dog of approximately 2 years who was attended at the Uberlândia Federal University (UFU) veterinary hospital in Uberlândia, Minas Gerais, Brazil. The dog exhibited clinical and laboratory signs of the disease and was reactive in serological tests and positive by PCR. The animal was treated with $2 \mathrm{mg} / \mathrm{kg}$ oral miltefosine once daily (SID) for 28 days, $10 \mathrm{mg} / \mathrm{kg}$ allopurinol twice daily (BID) continuous use and $0.5 \mathrm{mg} / \mathrm{kg}$ domperidone once daily (SID) for 60 days. The animal was monitored for clinical signs and laboratory abnormalities every 30 days after initiation of treatment over a 3-month period. After 3 months it returned, for PCR-RT to quantify the parasite load. According to the clinical and laboratory findings, miltefosine as a combination therapy has been shown to be effective in the treatment of LVC.

KEYWORDS: dog, leishmania, treatment.

\section{INTRODUÇÃO}

A leishmaniose visceral canina (LVC) é uma doença de caráter zoonótico, que acomete os seres humanos e diversas espécies de animais silvestres e domésticos. É causada pelo protozoário Leishmania chagasi, espécie semelhante à Leishmania infantum e tem como principal vetor o flebotomínio Lutzomyia longipalpis. O cão doméstico é considerado o principal reservatório do protozoário, devido principalmente à maior proximidade com os seres humanos e à alta susceptibilidade à infecção (BANETH et al., 2008; SILVA et al., 2011; MENDONÇA et al., 2015).

Os sinais clínicos em cães naturalmente infectados por LVC são variáveis e dependem da imunocompetência do animal. Dentre as alterações mais frequentes, destacam-se as dermatológicas, emagrecimento, linfadenopatia, oftalmopatias, mucosas pálidas, onicogrifose, hepatoesplenomegalia dentre outros. Porém os cães infectados podem permanecer assintomáticos por um longo período de tempo (GÓMEZ-OSHOA et al., 2007; LARSSON; LUCAS, 2016).

Segundo Barçante (2017) a LVC representa um grave problema de saúde pública e é considerada uma doença potencialmente fatal, se não tratada precocemente e de forma adequada. Cerca de $90 \%$ dos casos de LVC ocorrem em cinco países: Índia, Bangladesh, Nepal, Sudão e Brasil. Em 2014, foi reportado nas Américas um total de 3624 casos de leishmaniose visceral e desses, 95\% seguem ocorrendo no Brasil, atingindo as cincos regiões brasileiras e 21 dos seus estados. A região nordeste é responsável por quase $50 \%$ dos casos do país (OPS/OMS, 2016).

De acordo com Ribeiro (2007) a Organização Mundial da Saúde recomenda o sacrifício de cães como medida ideal de controle da LVC. Ribas et al. (2013) demonstraram através de um modelo matemático, que a eutanásia não é a forma mais eficaz no controle da leishmaniose visceral em cães soropositivos; de acordo com esse modelo, a combinação de coleiras impregnadas de inseticidas e o controle vetorial têm um impacto mais significativo na disseminação em humanos.

Em 11 de julho de 2008 foi publicada no Brasil, a portaria interministerial $n^{\circ}$ 1.426 dos Ministérios da Saúde e da Agricultura, Pecuária e Abastecimento (MAPA), proibindo o tratamento de LVC com produtos de uso humano ou não registrados no MAPA. Em países em que o tratamento é permitido, os principais medicamentos utilizados são os antimoniais pentavalentes, o alopurinol, a aminosidina, a anfotericina $B$ e a miltefosina, empregados de forma isolada ou em associação (LARSSON; LUCAS, 2016). O antimoniato de meglumina (Glucantime $\circledR$ ) é o medicamento de escolha para o tratamento de LVC humana e tem sido o mais 
utilizado como protocolo de tratamento para cães. Porém, devido a relatos de resistência ao tratamento humano com Glucantime, foram necessárias novas estratégias e opções de tratamento para LVC (WOERLY, 2009).

Recentemente, uma nova droga baseada em miltefosina (Milteforan $\AA$ Virbac) teve seu registro autorizado na nota técnica conjunta $n^{\circ} 001 / 2016$ - MAPA/MS para o uso veterinário, no tratamento de LVC.

O objetivo desse estudo foi avaliar a eficácia da miltefosina como terapia combinada no protocolo de tratamento da LVC e acompanhar as alterações do ponto de vista clínico e laboratorial de uma cadela durante um período de 12 semanas.

\section{RELATO DE CASO}

Foi atendida no hospital veterinário da Universidade Federal de Uberlândia (UFU), no estado de Minas Gerais (MG), uma cadela, sem raça definida (SRD), de aproximadamente dois anos de idade. A tutora desconhecia o histórico do animal, uma vez que este havia sido resgatado no mesmo dia da consulta. $\mathrm{O}$ animal foi submetido ao exame clínico de rotina, em que observou-se necrose da extremidade de orelhas, alopecia e descamação de espelho nasal, blefarite, conjuntivite, edema de córnea, onicogrifose, alopecia periocular, descamação furfurácea generalizada (figura $1 \mathrm{~A}$ e B) e lesão ulcerativa na face interna da coxa (figura 1C). $\mathrm{O}$ animal apresentava-se normotérmico, apático, mucosas visíveis normocoradas, e à palpação foi observado linfadenomegalia generalizada e esplenomegalia.

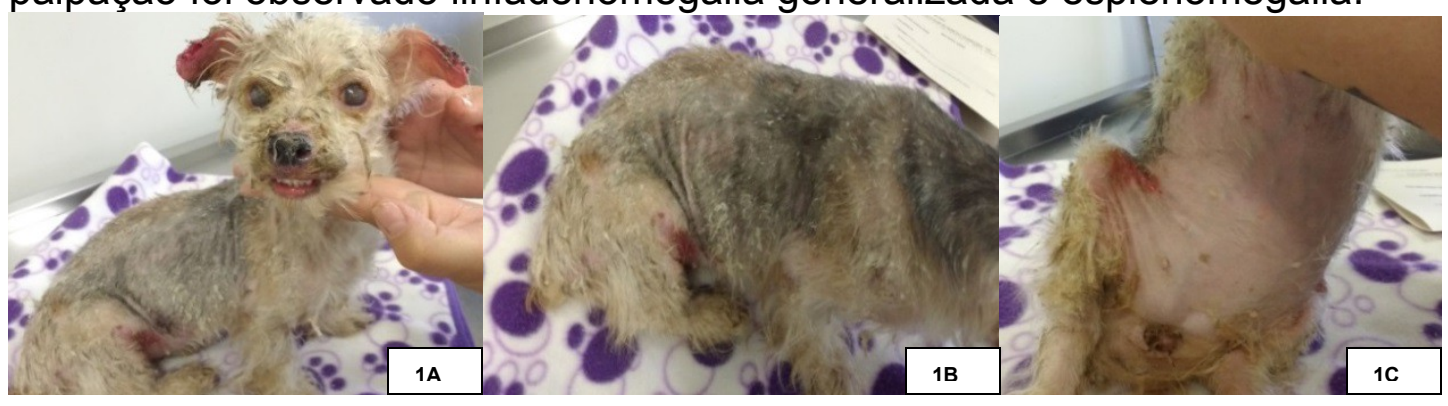

Fonte: Arquivo pessoal.

FIGURA 1: Apresentação clínica das lesões de pele da paciente. Figura 1A: notar a necrose da extremidade de orelhas, alopecia e descamação de espelho nasal, blefarite, conjuntivite, edema de córnea, alopecia periocular. Figura 1B:descamação furfurácea generalizada evidente. Figura 1C: lesão ulcerativa em face interna da coxa.

Foram coletados em tubo estéril e imediatamente acondicionadas em caixas isotérmicas, cerca de $4 \mathrm{~mL}$ de sangue, sem anticoagulante, por venopunção da jugular. A amostra foi enviada para o Centro de Controle de Zoonoses (CCZ) de Uberlândia - MG para realização do teste imunocromatográgico rápido Dual Plack Platform (DPPTM) e confirmação com o Enzyme Linked Immunosorbent Assay (ELISA).

Em função do resultado reagente no teste rápido e ELISA, foram coletadas novas amostras de sangue e urina para realização de hemograma e exames bioquímicos (creatinina, albumina, proteína total e UPC), para estadiamento da doença. Também foi realizado PCR para erliquiose, babesiose e anaplasmose para descartar infecções concomitantes com hemoparasitas, e até mesmo para evitar uma possível reação cruzada resultando em um diagnóstico falso-positivo. Realizou- 
se aspiração dos linfonodos mandibulares e poplíteos, diluído em $0,2 \mathrm{~mL}$ de solução salina e acondicionados em tubo eppendorf para detecção do DNA da leishmania, por meio da reação em cadeia de polimerase em tempo real quantitativo (PCR-RT) com intuito de confirmar o diagnóstico de LVC e determinar a carga parasitária para auxiliar no monitoramento da doença.

As anormalidades mais evidentes observadas no hemograma na primeira consulta, foram anemia (indicada por uma diminuição na contagem de hemácias e hematócrito além de hemoglobinemia), trombocitopenia e desvio a esquerda degenerativo (tabela 1). Nos parâmetros bioquímicos, as anormalidades foram tipicamente caracterizadas por hipoalbuminemia e uma proporção diminuída de albumina/globulina. Os valores bioquímicos relacionados ao sistema renal (ureia, creatinina e UPC) encontravam-se dentro dos padrões de referência (tabela 2).

$O$ resultado dos PCRs para as hemoparasitoses foram negativos e a cadela foi positiva no exame de PCR-RT para Leishmania, apresentando 221,65 cópias de DNA patógeno por $\mu \mathrm{L}$ de amostra extraída (tabela 3 ). Devido às alterações oculares, foram realizados o Teste de Schirmer (olho direito $3 \mathrm{~mm} /$ olho esquerdo $5 \mathrm{~mm}$ ) e o Teste de Fluoresceína (negativo em ambos os olhos) confirmando a presença de Ceratoconjuntivite seca com ausência de úlcera de córnea, secundária a LVC.

O tutor optou pelo tratamento da doença respeitando o protocolo descrito na bula do produto Milteforan (Virbac). O tutor foi devidamente orientado sobre como evitar a transmissão da LVC, utilizando proteção química individual no animal e como proceder com controle ambiental do vetor por meio do uso de inseticidas.

$\mathrm{O}$ animal foi submetido a diversos tratamentos que incluíam antibioticoterapia sistêmica com o uso de amoxicilina + clavulanato de potássio na dose de $20 \mathrm{mg} / \mathrm{kg}$ a cada 12 horas (BID) durante 15 dias, terapia tópica com banhos semanais utilizando shampoos queratolíticos à base de peróxido de benzoíla durante 30 dias, sprays hidratantes pós banhos e ampolas semanais com repositores de barreira cutânea, durante 30 dias. A terapia oftálmica consistiu em colírios à base de tobramicina a cada oito horas (TID) durante sete dias, trometamol cetorolaco BID durante sete dias, acetato de prednisolona 1\% BID durante sete dias e substitutos de lágrimas a cada seis horas (QUID) durante 30 dias; posteriormente com a melhora do quadro clínico foi prescrito ao animal, como terapia oftálmica da manutenção, tacrolimus $0,03 \%$ uma vez ao dia (SID) até novas recomendações.

Baseado no tipo e intensidade dos sinais e anormalidades laboratoriais, a LVC do animal em estudo foi classificada como sendo do estágio II a. Foi iniciado o protocolo de tratamento com a miltefosina $2 \mathrm{mg} / \mathrm{kg}$ SID, durante 28 dias, alopurinol $10 \mathrm{mg} / \mathrm{kg}$ BID, uso contínuo e domperidona $0,5 \mathrm{mg} / \mathrm{kg}$ SID, durante 60 dias. O animal foi monitorado em relação aos sinais clínicos e alterações laboratoriais a cada 30 dias após o inicio do tratamento durante o período de três meses e a cada três meses para realização do PCR-RT para quantificar a carga parasitária.

Os resultados dos exames de hemograma e bioquímicos a cada 30 dias encontram-se nas tabelas 1 e 2 e os resultados do PCR-RT na tabela 3. No primeiro retorno após o tratamento, a paciente apresentou uma melhora significativa e evidente nas lesões oculares e de pele (figura 2 A, B, C e D), porém ainda foi observada linfadenomegalia e esplenomegalia à palpação. Nos exames de sangue e urina foi observada uma diminuição na série vermelha em comparação ao primeiro exame, aumento das plaquetas, normalização dos valores de bastonetes, diminuição do UPC, hiperalbuminemia e um discreto aumento na relação albumina/globulina. 
TABELA 1: Evolução dos parâmetros hematológicos da paciente em estudo, antes (R0) e a cada 30 dias (R1, R2, R3) após o tratamento

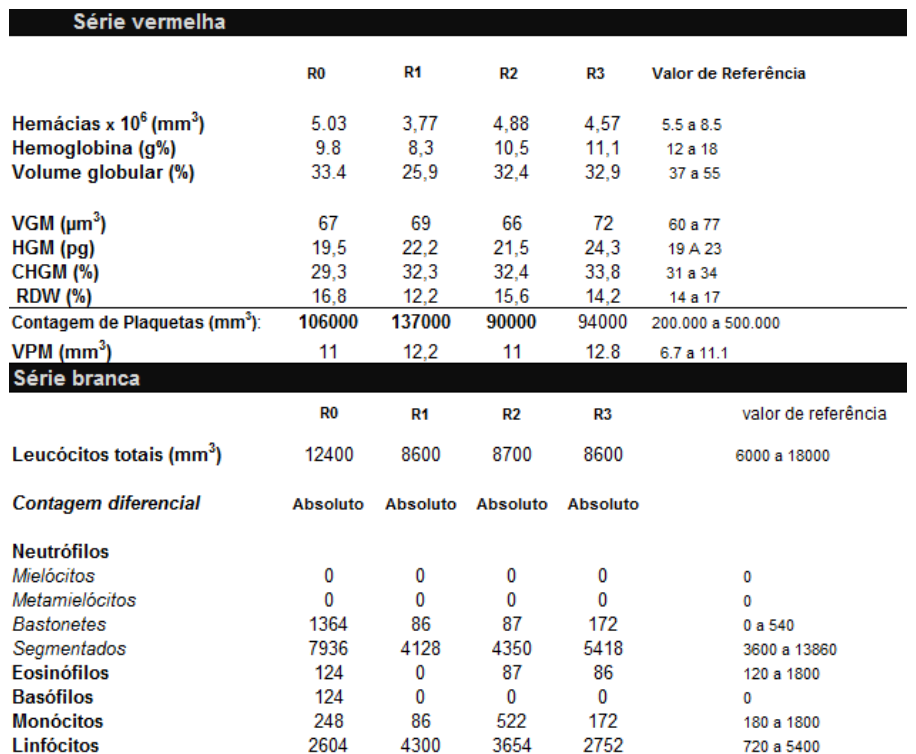

TABELA 2: Evolução dos parâmetros bioquímicos da paciente em estudo, antes (R0) e a cada 30 dias (R1, $\mathrm{R} 2, \mathrm{R} 3$ ) após o tratamento

\begin{tabular}{lccccc}
\hline \multicolumn{7}{c}{ Bioquimica } & & & & & \\
& R0 & R1 & R2 & R3 & Valor de Referência \\
Creatinina & & & & & \\
UPC & 0,51 & 0,83 & 0,80 & 0,76 & 0,5 a $1,5 \mathrm{mg} / \mathrm{dL}$ \\
Albumina & 0,48 & 0,3 & 0,1 & 0,1 & \\
Proteina total & 1,62 & 2,15 & 2,24 & 2,5 & 2,6 a 3,3 g/dL \\
Globulinas & 10,07 & 10,05 & 10,08 & 8 & 5,4 a $7,1 \mathrm{~g} / \mathrm{dL}$ \\
Relação A/G & 8,45 & 7,9 & 7,8 & 5,5 & 2,7 a $4,4 \mathrm{~g} / \mathrm{dL}$ \\
& 0,19 & 0,27 & 0,28 & 0,46 & 0,59 a 1,11
\end{tabular}

TABELA 3: PCR em tempo real quantitativo Leishmania (L.) infantum chagasi do animal em estudo. R0: antes do tratamento. R3: três meses após o tratamento

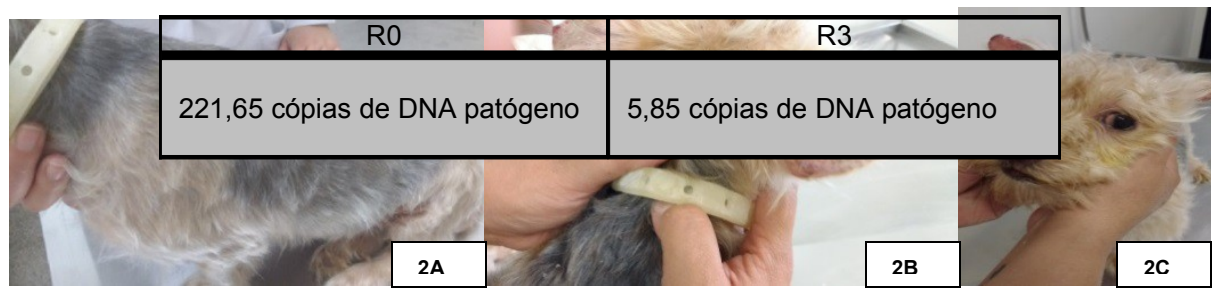

Fonte: Arquivo pessoal. 


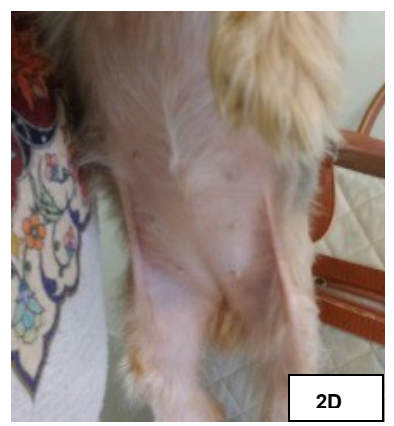

Fonte: Arquivo pessoal.

FIGURA 2: Apresentação clínica 30 dias após o tratamento. 2 A e B: nota-se melhora na descamação furfurácea e cicatrização da lesão nas extremidades das orelhas. 2C: presença de repilação e melhora da lesão descamativa na região do focinho. Notar também a melhora clínica das lesões oculares. 2D: notar a cicatrização da lesão ulcerativa na face interna da coxa.

O tutor referiu presença de alguns carrapatos no animal no período do tratamento, e como houve uma piora da anemia, foi coletada uma amostra de sangue para realizar novamente o PCR de erliquiose, babesiose e anaplasmose que resultou negativo. Foi também relatado que a paciente apresentou alguns episódios de vômitos na segunda semana de tratamento, porém cessaram espontaneamente e não provocaram efeitos importantes clinicamente.

Após dois meses de tratamento, o animal continuou apresentando melhora do quadro clínico (figura 3), porém ainda apresentou anormalidades nos exames de hemograma e bioquímicos. Observou-se melhora da anemia, trombocitopenia, eosinopenia, aumento da albumina e da relação albumina/globulina e diminuição da UPC (tabela 1 e 2).

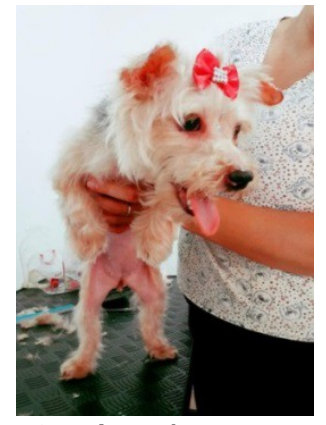

Fonte: Arquivo pessoal

FIGURA 3: paciente 2 meses após o tratamento sem alterações dermatológicas evidentes.

Após três meses de tratamento, foi observada uma diminuição significativa das globulinas, aumento da albumina e da relação albumina/globulina, sendo que esses parâmetros estão próximos aos valores de referência. Uma discreta anemia e trombocitopenia ainda foram observadas. Ao exame físico o animal não apresentava alterações dermatológicas evidentes, os linfonodos poplíteos já não estavam mais reativos, e os mandibulares apenas levemente aumentados. No exame de PCR-RT para Leishmania, foi observada uma relevante diminuição da carga parasitária. 


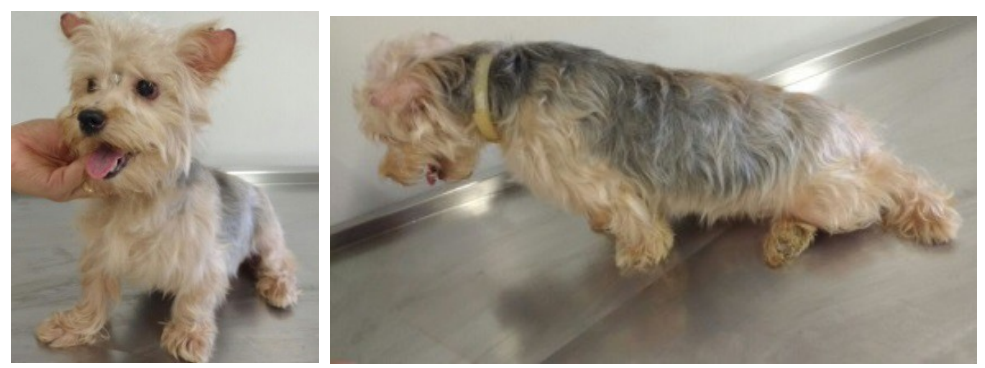

Fonte: Arquivo pessoal.

FIGURA 4: Paciente três meses após o tratamento, apresentando ausência de alterações dermatológicas evidentes.

\section{DISCUSSÃO}

O presente relato trata-se de uma cadela, de aproximadamente dois anos de idade que foi diagnosticada com LVC. Os achados clínicos são condizentes com aqueles descritos por Linhares (2005) e Solano-Gallego et al. (2011).

O diagnóstico da LVC é complexo e desafiador, pois não existem testes $100 \%$ sensíveis e específicos. No animal em estudo, foi realizado o teste rápido para posterior confirmação por meio do ELISA conforme recomendado por Laurenti et al. (2014). De acordo com Pinto et al. (2016) atualmente essa é a estratégia oficial do programa de controle da LVC do Ministério da Saúde, sendo que o uso do teste rápido associado ao ELISA aumentou a acurácia e a sensibilidade em relação aos cães verdadeiramente positivos, principalmente em áreas endêmicas.

Devido a ambos os testes sorológicos terem sido reagentes, foram coletadas novas amostras de sangue e urina para exames de hemograma, bioquímicos e UPC para o estadiamento da doença, etapa fundamental após o diagnóstico. 0 estadiamento consiste em um sistema de quatro estágios clínicos baseados nas alterações observadas no exame físico com as alterações dos exames laboratoriais, para auxiliar na escolha do tratamento e na determinação do prognóstico da doença (SOLANO-GALLEGO et al., 2009; LARSSON; LUCAS, 2016). Baseado nos estudos dos autores citados, o paciente foi classificado no estádio lla (doença moderada) apresentando um prognóstico de bom a reservado.

De acordo com Miró et al. (2009) os PCRs para as hemoparasitoses foram realizados para evitar uma possível reação cruzada e um diagnóstico falso-positivo. A técnica de PCR em tempo real foi realizada através do aspirados de nódulos linfáticos, devido a sua alta sensibilidade e especificidade, para confirmação do diagnóstico e também, por meio dela é possível detectar a carga parasitária da amostra biológica, sendo essa uma importante informação para o monitoramento da doença (SOLANO-GALLEGO et al., 2009; MANA et al., 2009; NOLI; SARIDOMICHELAKIS, 2014).

As principais alterações laboratoriais encontradas foram anemia, trombocitopenia, hiperproteinemia, hipoalbuminemia e uma redução na proporção albumina/globulina (tabela 1 e 2), corroborando com os estudos de Woerly et al. (2009); Solano-Gallego et al. (2009); Solano-Gallego et al. (2011).

O protocolo de tratamento instituído foi à associação da miltefosina com alopurinol e domperidona. De acordo com os estudos de Miró et al., (2009); SolanoGallego (2009); Larsson e Lucas (2016) o alopurinol, por ser uma droga leishmaniostática, possui uma ação efetiva quando combinada com outras medicações. Muitos veterinários mantêm seu uso por toda a vida do animal, pois com a sua interrupção, as recidivas do quadro clínico são frequentes. A 
domperidona, mesmo não exercendo atividade direta sobre as leishmanias, possui ação imunomoduladora e tem sido eficaz no controle e redução dos sinais clínicos de cães com LVC (GÓMEZ-OCHOA et al., 2007).

Os exames de hemograma e bioquímicos da paciente foram monitorados a cada 30 dias durante um período de três meses após o tratamento para efeito de estudo. De acordo com Solano-Gallego et al. (2009) e Roura et al. (2013), é recomendado realizar esses exames após um mês de tratamento, e depois a cada 3-4 meses durante o primeiro ano. Mais tarde, se houver a remissão completa dos sinais clínicos, seria recomendado a cada seis meses ou um ano. O PCR quantitativo foi realizado três meses após o tratamento, porque a carga parasitária é reduzida após um período de 3-12 meses do início da terapia (ROURA et al., 2013).

A miltefosina tornou-se uma importante droga no tratamento de LVC, devido ao diferente modo de ação, com base em uma atividade antiparasitária direta e não dependendo de sistema imunológico funcional, sua facilidade de administração, por via oral, e baixa toxicidade (MIRÓ et al., 2009), sendo sua eficácia clínica e laboratorial relatada nos estudos de Woerly et al. (2009); Miró et al., (2009); Andrade et al. (2011).

A miltefosina como terapia combinada, mostrou reduzir significativamente os sinais clínicos 30 dias após o tratamento e conforme mostrado na tabela 1 e 2, as anormalidades do hemograma e dos bioquímicos foram substancialmente reduzidas ao longo do período de tratamento. Observou-se uma redução na série vermelha 1 mês após a terapia, e segundo Alonso e Alonso (2016) em humanos o acúmulo da miltefosina na membrana celular, até atingir uma concentração suficiente para causar o efeito leishmanicida, resultam em danos à membrana dos eritrócitos, levando a hemólise, e provavelmente, esse potencial hemolítico também ocorreu no caso em estudo, porém foi transitório, obtendo melhora nos exames subsequentes. O notável é que nos meses posteriores ao período de não utilização da miltefosina, o efeito terapêutico persistiu, o que pode ser explicado pela propriedade farmacocinética particular da droga, que possui uma meia vida de eliminação longa (6,7 dias), levando a um alto nível de acumulação no plasma, após as repetidas doses diárias (WOERLY et al., 2009).

Semelhante ao descrito por Woerly et al. (2009) e Andrade et al. (2011) o único efeito adverso observado foi o vômito, porém foi reversível e auto limitante. Os resultados dos PCRs quantitativos (tabela 3) confirmam a eficácia do efeito leishmanicida da miltefosina associado ao alopurinol, reduzindo significativamente a carga parasitária três meses após o tratamento, corroborando com os estudos de Manna et al. (2009); Andrade et al. (2011).

\section{CONCLUSÃO}

O nosso estudo de caso mostrou que o uso da Miltefosina combinada com alopurinol e domperidona tem eficácia no controle dos sinais clínicos e redução de carga parasitária, representando, portanto, boa alternativa para os protocolos atuais no tratamento de LVC.

\section{REFERÊNCIAS}

ALONSO, L.; ALONSO, A. Hemolytic potential of miltefosine is dependent on cell concentration: Implications for in vitro cell cytotoxicity assays and pharmacokinetic data. Biochimica et Biophysica Acta - Biomembranes, v. 1858, n. 6, p. 1160- 
1164, 2016. Disponível em < https://www.ncbi.nlm.nih.gov/pubmed/26947181>. DOI:10.1016/j.bbamem.2016.03.004.

ANDRADE, H. M;TOLEDO, V.P.C.P; PINHEIRO,M.B; GUIMARÃES,T.M.P.D; OLIVEIRA, N.C, et al. Evaluation of miltefosine for the treatment of dogs naturally infected with L. infantum (=L. chagasi) in Brazil. Veterinary Parasitology, v. 181, n. 2-4, p. 83-90, 2011. Disponível em < https://www.sciencedirect.com/science/.../S0304401711003293>.DOI:10.1016/j.vetp ar.2011.05.009.

BANETH, G; KOUTINAS, A.F; SOLANO-GALLEGO, L; BOURDEAU, P; FERRER, L. Canine leishmaniosis - new concepts and insights on an expanding zoonosis: part one. Trends Parasitol 24(7):324-330, 2008. Disponível em < https://www.ncbi.nlm.nih.gov/pubmed/18514028> DOI: 10.1016/j.pt.2008.04.001.

BARÇANTE, J.M.P. Urbanização e Leishmaniose. Revista pré.univesp, $n^{\circ} 61$, dez 2016/ jan 2017. Disponível em < http://pre.univesp.br/urbanizacao-eleishmaniose\#.WnJsILynHIV>, acesso no dia 18 de dezembro de 2017.

BRASIL. Ministério da Agricultura, Pecuária e Abastecimento e Ministério da Saúde. Registro do produto de uso veterinário denominado Milteforan $2 \%$ Solução Oral para cães. Nota técnica conjunta n001/2016- MAPA/MS, de 17 de agosto de 2016. Disponível em < http://www.sbmt.org.br/portal/wp-content/uploads/2016/09/notatecnica.pdf>, acesso no dia 29 de janeiro de 2018.

BRASIL. Ministério da Saúde. Proíbe o tratamento de leishmaniose visceral canina com produtos de uso humano ou não registrados no Ministério da Agricultura, Pecuária e Abastecimento. Portaria interministerial $n^{0} 1.426$, de 11 de julho de $2008 . \quad$ Disponível em <http://bvsms.saude.gov.br/bvs/saudelegis/gm/2008/pri1426_11_07_2008.html>, acesso no dia 31 de janeiro de 2018.

GÓMEZ-OCHOA, P; CASTILLO, J. A; GASCÓN, M; ZARATE, J. J; ALVAREZ, F, et al. Use of domperidone in the treatment of canine visceral leishmaniasis: A clinical trial. Veterinary Journal, v. 179, n. 2, p. 259-263, 2009. Disponível em < https://www.ncbi.nlm.nih.gov/pubmed/18023375>. DOI: 10.1016/j.tvjl.2007.09.014.

LARSSON, C. E; LUCAS,R. Tratado de Medicina Externa: Dermatologia Veterinária. São Caetano do Sul: Interbook, p. 313-344.2016.

LAURENTI, M. D; JUNIOR, M.V.S.L;TOMOKANE, T.Y; LUCCA, H.R.L; ASCHAR, M, et al. Comparative evaluation of the DPP ${ }^{\circledR}$ CVL rapid test for canine serodiagnosis in area of visceral leishmaniasis. Veterinary Parasitology, v. 205, n. 3-4, p. 444-450, 2014.Disponívelem<https://pdfs.semanticscholar.org/.../2ca4ddfe47fa8c6db9b74447 3>.DOI:10.1016/j.vetpar.2014.09.002.

LINHARES, G.F.C; CHAVES, N.S.T; DUARTE, S.C; FERNANDES, P.R; AMARAL, A.V.C, et al. Relato de caso. Relato de um caso clínico de leishmaniose visceral. v. $34, \quad$ n. $62, \quad$ p. 69-72, 2005. Disponível em < 
https://www.revistas.ufg.br/iptsp/article/download/2140/2085>, acesso dia 20 de dezembro de 2017.

MANNA, L; VITALE, F; REALE, S; PICILLO, E; NEGLIA, G, et al. Study of efficacy of miltefosine and allopurinol in dogs with leishmaniosis. Veterinary Journal, v. 182, n. 3, $\quad$ p. 441-445,2009.Disponível em:<https://www.ncbi.nlm.nih.gov/pubmed/18818112>DOI:10.1016/j.tvjl.2008.08.009

MENDONÇA, I.L; ALVES,M.M.M; BATISTA,J.F; ROCHA, F.S.B; SILVA, E.M.C. Alterações bioquímicas e hematológicas em cães naturalmente infectados por Leishmania (infantum) chagasi. Clínica veterinária, ano XX, n.116, p.78- 84,2015.

MILTEFORAN. Responsável técnico: Valdir Carlos Avino. São Paulo: VIRBAC saúde animal, 2016. Bula de remédio. Disponível em <https://br.virbac.com/home/produtos/caes/antiparasitariosinternos/main/antiparasitar ios-internos/milteforan.html> , acesso no dia 8 de fevereiro de 2018.

MIRÓ, G; OLIVA, G; CRUZ, I; CANAVATE, C; MORTARINO, M, et al. Multicentric, controlled clinical study to evaluate effectiveness and safety of miltefosine and allopurinol for canine leishmaniosis. Veterinary Dermatology, v. 20, n. 5-6, p. 397404, 2009. Disponível em < https://www.ncbi.nlm.nih.gov/pubmed/20178476> DOI: 10.1111/j.1365-3164.2009.00824.x.

NOLI, C.; SARIDOMICHELAKIS, M. N. An update on the diagnosis and treatment of canine leishmaniosis caused by Leishmania infantum (syn. L.-chagasi). Veterinary Journal, v. 202, n. 3, p. 425-435, 2014. Disponível em < https://www.ncbi.nlm.nih.gov/m/pubmed/25266647> DOI: 10.1016/j.tvjl.2014.09.002.

ORGANIZAÇÃO PANAMERICANA DA SAÚDE: Leishmanioses: Informe Epidemiológico nas Américas: Washington: Organização Panamericana da Saúde; 2016. Disponível em < www.paho.org/leishmaniosis>, acesso no dia 15 de dezembro de 2017.

PINTO, A.J.W; RIBEIRO, V.M; TAFURI, W.L. Análise do diagnóstico de leishamaniose visceral canina no Brasil, com ênfase no uso dos métodos sorológicos: teste imunocromatográfico, ELISA e reação de imunofluorescência indireta - revisão de literatura. Clínica Veterinária, ano XX, n.123, p.80-86, 2016.

RIBAS, L.M; ZAHER, V.L; SHIMOZAKO, H.J; MASSAD, E. Estimating the Optimal Control of Zoonotic Visceral Leishmaniasis by the Use of a Mathematical Model. The Scientific World Journal, 2013. Disponível em < https://www.hindawi.com/journals/tswj/2013/810380/> DOI: 10.1155/2013/810380.

RIBEIRO, V.M. Leishmaniose visceral canina: aspectos de tratamento e controle. Clínica veterinária, $n^{071}$, p.66-76, 2007.

ROURA, X; FONDATI, A ;LUBAS, G; GRADONI, L; MAROLI, M, et al. Prognosis and monitoring of leishmaniasis in dogs: A working group report. Veterinary Journal, v. 198, n. 1, p. 43-47, 2013.Disponível em < https://www.ncbi.nlm.nih.gov/pubmed/23680263> DOI: 10.1016/j.tvjl.2013.04.001. 
SILVA, D.A; PERLÉ, C.S.F.S; JUNIOR, A.A.V.M; MADEIRA, M.F; FIGUEIREDO,F.B. Leishmaniose visceral canina em Cachoeiras de Macacu, Rio de Janeiro - relato de caso. Clínica veterinária, n.95, p.64-68, 2011.

SOLANO-GALLEGO, L; KOUTINAS, A; MIRÓ, G; CARDOSO, L; PENNISI, M.G, et al. Directions for the diagnosis, clinical staging, treatment and prevention of canine leishmaniosis. Veterinary Parasitology, v. 165, n. 1-2, p. 1-18, 2009.Disponível em< https://www.ncbi.nlm.nih.gov/pubmed/19559536>

DOI: 10.1016/j.vetpar.2009.05.022.

SOLANO-GALLEGO, L; MIRÓ, G; KOUTINAS, A; CARDOSO, L; PENNISI, M.G, et al. LeishVet guidelines for the practical management of canine leishmaniosis. Parasites and Vectors, v. 4, n. 1, p. 1-16, 2011.Disponível em < https://parasitesandvectors.biomedcentral.com/.../1756-3305-4-86> DOI: 10.1186/1756-3305-4-86.

WOERLY, V; MAYENARD,L; SANQUER, A; HYONE-MYONG EUN. Clinical efficacy and tolerance of miltefosine in the treatment of canine leishmaniosis. Parasitology Research, v. 105, n. 2, p. 463-469, 2009. Disponível em < https://trove.nla.gov.au/work/78397085> DOI: 10.1007/s00436-009-1404-2. 